\title{
Knowledge management in a railway network: The case of signalling systems
}

\author{
Amparo Morant ${ }^{1}$, Mats Westerberg ${ }^{2}$, Per-Olof Larsson-Kråik ${ }^{1,3}$ \\ ${ }^{1}$ Luleå Railway Research Centre, Division of Operation, Maintenance and \\ Acoustics, Luleå University of Technology, Luleå, Sweden \\ 2 Division of Innovation and Design, Luleå University of Technology, Luleå, \\ Sweden \\ ${ }^{2}$ Swedish Transport Administration, Trafikverket, Sweden
}

\begin{abstract}
The railway network is a complex system with several technologies and a multitude of stakeholders working together to solve problems created by the increasing demands on capacity, speed and mobility for the transportation of goods and passengers. However, the presence of many different stakeholders complicates knowledge management and transfer. The purpose of this paper is to analyse the potential for improving inter-organisational knowledge management in the maintenance of railway signalling systems and make concrete suggestions for improvements. Even if information logistics processes can disseminate explicit knowledge on the maintenance of railway signalling systems, they cannot handle the tacit knowledge transfer that often is crucial. The study finds considerable potential for improving the knowledge management process. It suggests possible measures and makes suggestions for future studies.
\end{abstract}

Keywords: Railway, signalling systems, maintenance, knowledge management, inter-organisational learning, knowledge transfer, know-how.

\section{Introduction}

The Swedish Transport Administration's total budget is SEK 51.9 billion; on which the major investments have primarily been made in the railway system [1]. The traffic volume for passengers on the public railways amounted to 97 million train kilometres in 2012; the traffic volume for railway goods transport flows on stateowned tracks amounted to 42.9 million train kilometres and volumes for rail transport were 21.0 billion tonne kilometres in 2012 [1].

Sweden has a deregulated railway network system, and approximately 20 companies use the Swedish state's rail infrastructure [2]. The maintenance of the 
railway network (rolling stock and infrastructure) is also managed by many different companies. The Swedish Transport Administration (Trafikverket) is responsible for making investments in the railway infrastructure and maintaining it, as well as forming the long-term national transport policy [2]. Therefore, in this paper, Trafikverket is referred to as both infrastructure manager and transport administrator.

During the operation and maintenance of the railway infrastructure, lots of data are collected and managed in an attempt to control and analyse the current state of the system. Data include the system architecture, maintenance reports, work orders performed, etc. The railway can be divided into different systems depending on functionality, such as the rolling stock, the track, the power supply, the signalling system, etc. [3]. Signalling systems play an important role in the control, supervision and protection of rail traffic and their availability affects the performance of the whole system. A signalling system is a complex combination of software and hardware; the maintenance manager must understand how changes will affect the system, how the system is built, what role the different parts play and how they are interconnected. If up-to-date documentation is lacking, maintainers have serious problems [4]. The complexity of signalling systems makes knowledge management a necessity to ensure proper performance in all phases of the life cycle.

Signalling systems supervise and control the railway operation with different technologies installed both in the infrastructure along the track and in the rolling stock. To be able to operate on a specific railway corridor, a train requires the same signalling system that is in the infrastructure. Therefore, state companies such as Transitio or Rikstrafiken (via ASJ) provide operators with the necessary rolling stock [2]. In the maintenance area, the train records can help identify failures, since they record information received from the infrastructure. Clearly, sharing knowledge between all railway stakeholders in both the operation and maintenance of signalling systems is crucial.

Railway managers must have a holistic view of the railway systems (particularly signalling systems due to their need to be interoperable) to optimise maintenance. The managers responsible for determining maintenance actions face an abundance of data and have a complicated task transforming this data into information that will support maintenance actions [5]. In addition, confusing data/remarks in the databases often lead to misinterpretations. Structured databases containing the complete information are required to identify where failures are located and the dominant factors causing them [6]. Without well-functioning maintenance, the railway infrastructure would quickly lose its efficiency.

Maintenance support performance can be improved by considering the item structure and/or the organisation providing maintenance [7]. However, an information logistics system does not ensure that the proper personnel will acquire the knowledge, or that the know-how will be stored and transferred. To address this 
issue, this study focuses on the organisational structure of railway maintenance and operation.

The presence of many different stakeholders running the maintenance and operation of the railway network calls for a functioning knowledge transfer between them if the desired results are to be achieved. Each stakeholder has different knowledge access and needs. However, all stakeholders work on the railway systems, and knowledge transfer between departments and the dissemination of best practices can benefit everyone. Iacono et al.[8] explored the relationship between the design of inter-organisational connections, processes of knowledge creation and transfer, and innovation in a medium-large Italian company in the rail industry sector and compared these to a research consortium. The found that better efficiency of maintenance activities can be achieved by taking advantage of the available maintenance knowledge, thus contributing to time and costs savings [9].

When outsourcing maintenance activities, there is a risk of losing the knowledge of how to perform these activities [10,11]. This can be a problem if an out-sourced company lacks the required knowledge. It can also pose difficulties when changes or improvements in a system's design lead to changes in the maintenance. Knowledge transfer among people doing the outsourcing is not as direct as among people belonging to the same company. And while explicit knowledge transfer can be ensured by codifying knowledge, tacit knowledge is more difficult to transfer. Hence, the need to provide new procedures for knowledge transfer between companies.

The purpose of this paper is to analyse the potential for improving interorganisational knowledge management in the maintenance of railway signalling systems and make concrete suggestions for improvements. It identifies areas of improvement in the railway signalling systems' maintenance performance, and discusses how different theories of inter-organisational knowledge management can be applied to improve the maintenance and operation of the railway network, by looking at particular signalling systems.

\section{Railway signalling systems}

The research is based on the architecture of the railway infrastructure implemented in Sweden [15]. The two main systems of control and supervision are: ATC (Automatic Train Control) and ERTMS (European Railway Train Management System). Previous studies have pointed out the relevance of signalling systems and failure identification in maintenance performed on the Swedish railway network $[12,13,14]$. The signalling system is composed of the following sub-systems:

- Interlocking (IXL) / Radio Block Centre (RBC): receives input from the different systems (e.g. track circuits, level crossings, signals, TMS), calculates and returns as an output the train operation restrictions to ensure safe traffic operation.

- Track circuits: responsible for the train location. 
- Balise group: input from the track to the onboard signalling system (e.g. speed limits, driving mode, etc.).

- Level crossings: coordinate the road traffic crossing the railroad.

- Traffic management system (TMS): interface between the traffic operator and the railway network.

- Signals: give or restrict permission to the train to enter a track section.

- Signalling boards: inform the train of fixed information (e.g. tunnels, bridges, speed restriction area, etc.).

\section{Railway stakeholders}

Different stakeholders can be present during the operation and maintenance of the railway infrastructure, depending on the policies of the country. An example of these stakeholders is given in this section, using the Swedish railway system. Different information needs can be identified, depending on the work performed (e. g. operation management, corrective or preventive maintenance, RAMS (reliability, availability, maintainability and safety) studies, safety management, etc.); in addition, different companies are involved in the process, and each will have its own needs:

- Infrastructure manager: owns the public transport infrastructure and is responsible for its maintenance; also responsible for the transport planning infrastructure.

- Operators: responsible for train operation (passengers and freight).

- Maintenance companies: subcontracted to perform the maintenance on the train or the infrastructure

- Railway manufacturers: design and produce railway systems (rolling stock, infrastructure, signalling systems, etc.) depending on the requirements of the customer; customers include Swedish infrastructure manager, operators, maintenance companies or other manufacturers.

- Consultancy companies: perform regular studies to analyse maintenance or operation performance and suggest improvements.

Other stakeholders can be identified, not depending on the organisation but on the work performed. These include:

- Project manager: in charge of the development and implementation of a particular solution for the railway system.

- RAMS manager: responsible for ensuring that the system fulfils the safety requirements to operate; also analyses the RAMS parameters to measure the system performance and propose improvements.

- Maintenance manager: implements programs and procedures to ensure the optimal operation of the various railway systems.

- Maintenance personnel: performs corrective and preventive maintenance.

- Logistics manager: organises the inventory and distribution of railway assets.

- etc. 
Clearly, a wide variety of stakeholders take part in the operation and maintenance performance of the railway signalling systems, and it is logical to assume that some information and knowledge must be transferred among them. It can also be assumed that sharing knowledge will benefit all stakeholders, as general know-how will increase and the ability to cooperate will be strengthened.

As noted above, each stakeholder has different knowledge access and needs, but they are alike in that all work on the railway systems. The signalling system is more complex than some other systems, however, compounding the problem of knowledge sharing. An aspect setting signalling systems apart is their distributed location: part of the signalling system is located along the infrastructure and part on the rolling stock. Added to this, all systems must be interoperable to function (different signalling systems are not compatible), and if one of the subsystems is modified or updated, this will affect the rest of the components in the system. Hence, a framework to share knowledge is not only beneficial but actually needed for the smooth operation and maintenance of the signalling system. The knowledge transfer and dissemination of best practices between different stakeholders can thus benefit everyone.

\section{Dependability improvement through knowledge management}

Because it is impossible to get accurate results in the measurement of maintenance performance without having accurate information, knowledge management is crucial [9]. Luxhøj et al. [16] reviewed the relationship between maintenance improvement and organisational learning. They found that the maintenance knowledge base in a company is typically not well organised, structured, or current. Organisational learning can be defined as changes in organisational practices (including routines and procedures, structures, technologies, systems, and so on) that are mediated through individual learning or problem-solving processes [17].

Conducting effective and efficient maintenance requires accurate information and appropriate knowledge provisioning. Insufficient or inadequate maintenance support information leads to the "No Fault Found" (NFF) phenomenon [18]. Hockley and Phillips [19] explained the relationship between NFF and lack of training, sharing information and communication among others as organisational causes of NFF. Zhou et al. [20] proposed a fault knowledge management method to improve maintenance support performance. Horiguchi et al. [21] presented a new concept of the knowledge management framework for sharing technical know-how in an engineering community, using latent connections among technical keywords to search work reports for relevant references. Mansor et al. [9] proposed a knowledge repository or warehouse for maintenance activities consisting of four elements: best practice, databases, discussion forums and assessment tools. 
Information logistics processes can handle the dissemination of explicit knowledge but they cannot transfer tacit knowledge, as this depends partly on the expertise of the personnel.

\subsection{Outsourcing maintenance}

Campbell [10] described a framework to outsource maintenance, addressing such key aspects as objectives, readiness, alternatives, proposals and negotiations. Benefits of outsourcing include the following: the organisation is not limited to its own capabilities; suppliers can have more specialised personnel and better knowledge of a specific area; contractors can have more specialised equipment to perform a service, providing better quality and service at a lower price; outside sources do not require extended time to come up to speed on a new concept, as they are hired because they already possess knowledge and experience; permanent staff are exposed to outside specialists, giving them an opportunity to upgrade their skills [10].

Outsourcing activities have some risks: increased dependency on vendors; difficulty of building new relationships and managing relationships that go wrong; risk of communication and organisation problems; risk of leakage of confidential information; loss of critical skills or developing the wrong skills or losing control over critical functions; lowered morale of permanent employed employees; loss of cross-functional communication; loss of control over a supplier; less incentive to be innovative with short term contracts, based on the lowest winning bid $[10,11]$.

\subsection{Knowledge management}

Knowledge is personalised information related to facts, judgments, ideas, observations, etc. [22,23]. Knowledge can be classified according to how it is transmitted and articulated. Explicit or codified knowledge is transmittable in formal, systematic language, while tacit knowledge is linked to the individual and is very difficult to articulate $[23,24,25]$.

Thus, tacit and explicit knowledge have different methods of dissemination [24,25], and these must be addressed by knowledge management theories. Blumenberg et al. [24] showed that combined knowledge-transfer processes for tacit and explicit knowledge are more effective than are processes focused on one kind of knowledge (tacit or explicit). Their results also indicated that high levels of shared knowledge positively influence outsourcing performance [24]. On the model used by Toyota, explicit knowledge is disseminated by the supplier association, while tacit knowledge is transferred by the consulting / problem-solving division, the voluntary learning teams and the employee transfers [25]. 


\subsection{Inter-organisational knowledge management}

Due to the deregulated environment of the Swedish railway network, it is necessary not only to study the knowledge management processes of the different stakeholders but to optimise performance and maximise benefits by sharing best practices.

Lane and Lubatkin [26] determined that the ability of an organisation to learn from other organisations depends on the similarity of their respective knowledge bases, organisational structures, compensation policies, and dominant logics. Tsai (2001) used the concepts of network position and absorptive capacity to determine the effectiveness on inter-organisational learning and knowledge transfer. Findings indicated that organisational units can be more innovative and perform better if they occupy a central position in the inter-organisational network, but the result will depend on the company's capacity to replicate new knowledge [27].

The learning processes and outcomes of different people placed in the same task or job with the same learning potential will depend on their personal learning capabilities [17]. Ellström [17] defined four factors that affect learning integration:

- Learning potential in terms of task complexity, variety and control

- Feedback, evaluation and reflection opportunities

- Type and degree of formalisation of work processes

- Employee participation in handling problems and developing work processes

- Learning resources (e.g. time for analysis, interaction and reflection)

Lee and Van den Steen [28] proposed a model to explore the managerial decisions of a company that seeks to maximise the knowledge-based performance of its employees, describing the factors deciding which information is worth to record and manage, and who should have access to that information. In particular, they stressed the importance of recording best practices in the long term even when the performance varies over time, because the additional information serves as backup for when the best practice becomes obsolete [28].

Dyer and Nobeoka [25] showed that if the network can create a strong identity and coordinating rules, it will become an organisational form for creating and recombining knowledge, given the diversity of knowledge that resides within a network. They described Toyota's inter-organisational knowledge network and explained how Toyota has solved the three dilemmas of sharing knowledge: motivating members to participate and openly share valuable knowledge (while preventing undesirable spill-over to competitors), preventing free riders and reducing the costs associated with finding and accessing different types of valuable knowledge. Toyota's inter-organisational knowledge management network is based on three processes: a supplier association to facilitate sharing information; a Toyota's operations management division which gives support to all members of the network; a small group learning for knowledge sharing; and inter-firm employee transfers [25]. Toyota has also established some "rules" within the network that prevent members from protecting or hiding valuable knowledge and from free riding 
[25]: intellectual property rights are at the network level, not the firm level; the recipient of knowledge may appropriate $100 \%$ of the savings in the short run, but over time will be expected to share a proportion of those savings with the network (e.g., through price cuts to Toyota).

\section{Research methodology}

Our research is based on different companies related to the railway sector. A schema of the research methodology is shown in Figure 1. The corrective maintenance data processed for this study were obtained from Trafikverket. The data comprise work orders (WO) from January 2003 to November 2012 for a railway corridor $203 \mathrm{~km}$ long in the northern part of Sweden.

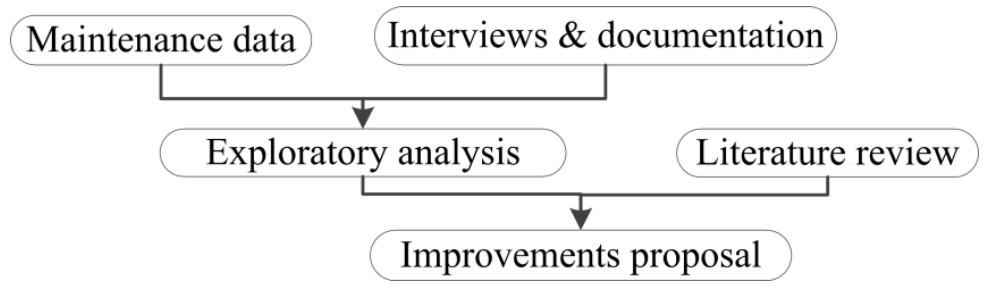

Figure 1: Research methodology.

We used a variety of empirical data to determine whether there is a need to improve the knowledge management of signalling systems. We performed an exploratory analysis on corrective maintenance data obtained from the infrastructure manager. The exploratory analysis identified whether the maintenance performance could be improved using knowledge management theories. By analysing the WOs related to corrective maintenance actions, it was possible to identify areas of improvement. The following information was collected from the WOs:

- Number of "No found failure" or "Not possible to define failure" WO.

- Number of work orders that were opened due to the same failure in a short range of time

- Time since the work order is opened (the failure is detected) until the WO is closed (the failure is repaired).

- Time to repair for each WO,

- Relation between the total time for the corrective maintenance (total time that the work order is opened) and the actual time to repair the failure.

We also used reports, unstructured interviews and scientific articles to determine how knowledge is managed and transferred between Trafikverket and the rest of the stakeholders involved on the maintenance of the signalling systems.

In addition to collecting data, we performed a literature review of current theories of knowledge management, organisational learning, know-how transfer, and knowledge dissemination. We focused on theories of knowledge management and dissemination in inter-organisational networks and outsourcing performance because of the number of different stakeholders in the railway. The literature review 
suggested several possibilities for improving the maintenance and operation of the railway network, particularly signalling systems. We detail these in following sections.

Admittedly, the research has some limitations. First, we did not analyse the data to determine quantitative measures of the effects of the knowledge management on the maintenance performance. This calls for further research and analysis. Second, present work is based on previous studies, and future research should seek to clarify the knowledge transfer between stakeholders (e.g. interviews with maintenance companies, manufacturers, etc.).

\section{Case study}

An analysis of the corrective maintenance data shows that signalling systems play an important role in corrective maintenance; $27 \%$ of the work orders were related to failures in signalling systems (see Figure 2, left). Yet this is one of the most critical systems in the railway network, because it ensures safe operation. Thus, improving maintenance would improve overall railway maintenance, and improvements in knowledge management for signalling systems would be applicable to other systems in the railway network.
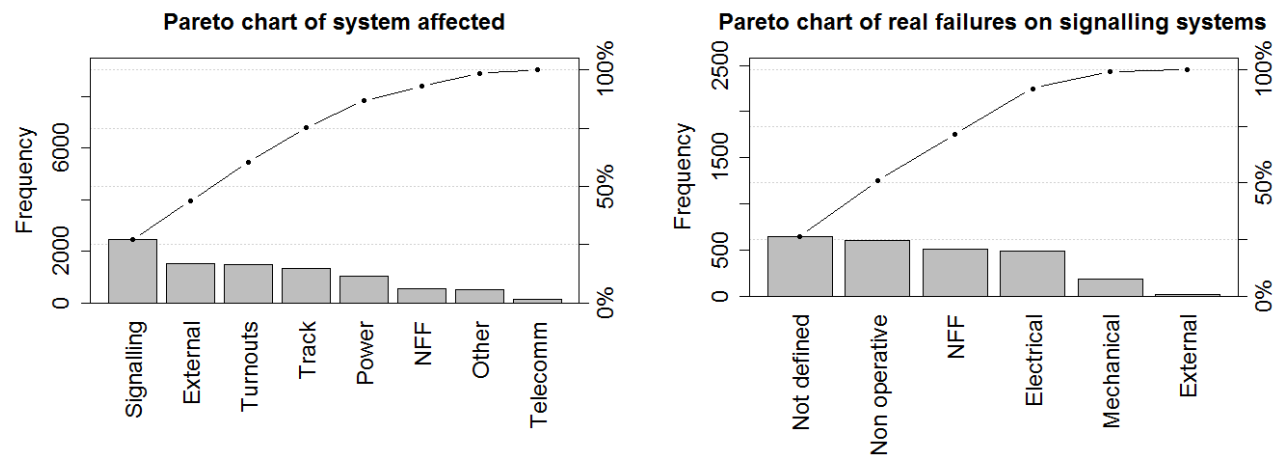

Figure 2: Left: Failure asset classification; Right: Real failure on signalling systems.

\subsection{No fault found phenomena}

Among the real failure modes recorded on the different WOs, a significant number noted "no failure found" or "could not identify the failure". For signalling systems, the percentage of WOs where the failure was not possible to define or no failure was found reached $47 \%$ (see Figure 2 right). Research in the area of the "no fault found" (NFF) shows the importance of this problem technically but also indicates organisational and behavioural aspects and proposes addressing it as an integrated problem $[18,19,29,30]$.

A practical example is given in Table 1. Four work orders are related to a failure reading an ATC code. The failed component was identified as belonging to the 
balise group. The first work order was open for four hours, with two hours dedicated to corrective action. In this example, no corrective actions were performed since it was not possible to identify the failure. Looking at the data, we see that the failure appeared three more times in the following days. The third work order related to the same failure, and this time the failure was assigned to the component related to the ATC (part of the subsystem of control and supervision of the interlocking system), but no failure was found. It was not until the fourth failure that corrective action was performed, and the component was replaced.

\begin{tabular}{|l|c|c|c|c|}
\hline \multicolumn{1}{|c|}{ Report label } & \multicolumn{4}{c|}{ Example case } \\
\hline Failure report ID & FRXXX1 & FRXXX2 & FRXXX3 & FRXXX4 \\
\hline Active repair time & $1 \mathrm{~h} .50 \mathrm{~min}$ & $15 \mathrm{~min}$ & $1 \mathrm{~h} .30 \mathrm{~min}$ & $1 \mathrm{~h}$. \\
\hline Symptom & Failure code ATC & Failure code ATC & Failure code ATC & Failure code ATC \\
\hline System & Balise group & Balise group & Interlocking / RBC & Interlocking / RBC \\
\hline Subsystem asset & - & - & $\begin{array}{c}\text { Control and } \\
\text { supervision }\end{array}$ & $\begin{array}{c}\text { Control and } \\
\text { supervision }\end{array}$ \\
\hline Component & No failure & No failure & $\begin{array}{c}\text { Not possible to } \\
\text { define }\end{array}$ & Bad contact \\
\hline Real failure & No reason known & No reason known & No reason known & $\begin{array}{c}\text { Material Fatigue / } \\
\text { Aging }\end{array}$ \\
\hline Cause & Control & Control & Control & Unit replacement \\
\hline Action performed & & & &
\end{tabular}

Table 1: Different work orders can be related to the same failure

The corrective data show that NFFs require extra time in corrective maintenance. Hence, improving knowledge management and promoting knowledge transfer can have an impact on the number of NFFs, reducing the work orders and the time spent performing corrective actions.

\subsection{Repair time}

The times spent on the work orders are particularly instructive. From the database, we can extract the following information on times and dates of corrective maintenance work orders: failure identification; WO opened; start of the corrective action; end of the corrective action and closure of the WO.

To analyse the data, we calculated the total time spent on the corrective action (TTM) given by Equation (1), the time on the repair action (TTR) given by Equation (2), and the relative repair time (RRT) against the total time for each WO given by Equation (3), analysing the general characteristics of each and the relationship between them.

$$
\begin{aligned}
& \text { TTM }=\mathrm{t}(\text { finish of corrective action })-\mathrm{t}(\text { failure identification }) \\
& \mathrm{TTR}=\mathrm{t}(\text { finish of corrective action })-\mathrm{t}(\text { start of corrective action }) \\
& \text { RRT }(\%)=\frac{\mathrm{TTR}(\mathrm{sec})}{\mathrm{TTM}(\mathrm{sec})}
\end{aligned}
$$


Table 2 shows the main parameters for the repair time and the time for maintenance, together with the relation between them, calculated as the relative repair time vs. total time. Approximately half the total time is repair time (43\%), but the relation is quite distributed; in some work orders TTM is equal to TTR, while in others, they are not comparable. Reasons for this vary: failure mode identification and specification of the needs required for repairing, distance to the failure location, human and /or material resources, etc.

Table 7. TTM, TTR and relative repair time (sec)

\begin{tabular}{|c|c|c|c|c|c|c|}
\hline & Min & 1st Qu. & Median & Mean & 3rd Qu & Max. \\
\hline TTM (sec.) & 180 & 4560 & 8700 & 16580 & 17400 & 86340 \\
\hline TTR (sec.) & 60 & 1260 & 3060 & 6094 & 6960 & 83880 \\
\hline RRT (\%) & 0.29 & 19.31 & 42.96 & 45.28 & 70,14 & 100.00 \\
\hline
\end{tabular}

Table 2: TTM, TTR and RRT

Figure 3 visually summarises the relative repair time depending on the system asset affected by the failure. This figure shows the maximum and minimum times spent, the median and the first and third quartiles. The density distribution is at the perimeter of the boxplots, and its width is given by the number of work orders associated with a failure of the system asset. We cannot make any generalisations about the relationship between TTM and TTR; the relationship varies differently, depending on the asset examined.

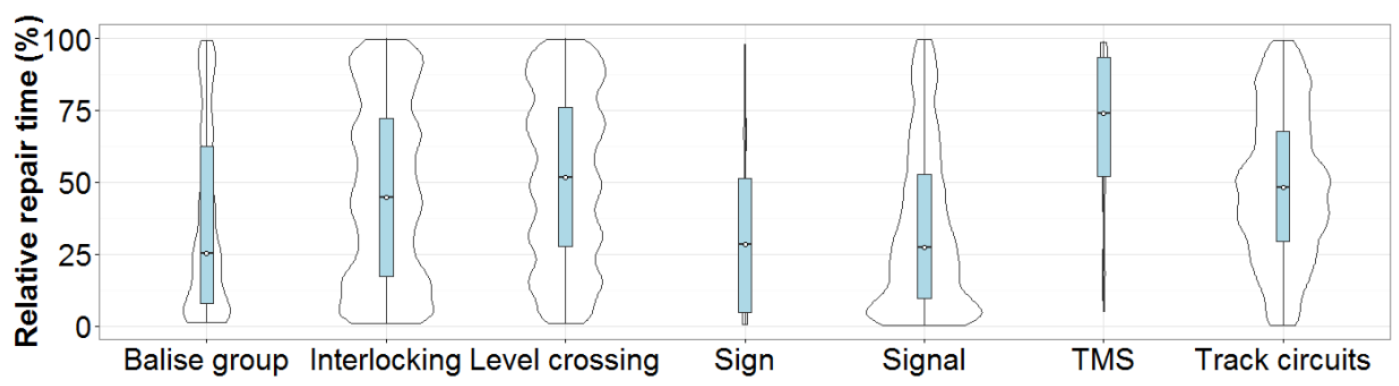

Figure 3: Relative repair time depending on system asset.

For system assets mostly affected by mechanical failures (e.g. signals, signal boards), the relative repair time is proportionally smaller, and the distribution of the relative repair time decreases when the values or TTR and TTM are more similar. Arguably, mechanical failures are easier to identify and these assets have a simpler architecture, thus facilitating repair or replacement and reducing TTR. The balise groups also have a smaller relative repair time, even though most failures are electronically based, due to the simplicity of its architecture.

For electronically based system assets with more complex architecture (e.g. interlocking, TMS), the relative repair time is proportionally higher than for mechanically based assets, and the distribution of the relative repair time does not show a trend. Possibly, more time is spent on identifying the occurred failure and finding the proper corrective action. 
NFFs are more common to electronically based systems, and the architecture of these systems is more complex. In such cases, having better knowledge of the systems to maintain can reduce the time required to identify the required corrective maintenance action.

\subsection{Knowledge management}

Trafikverket uses different types of contracts for the maintenance of the infrastructure; some are performance-based. The condition of the track is assessed before a contract is set up, and changes on the condition of the assets are linked to bonuses and fees [11,31]. All new contracts are performance-based with fixed payments for five years and an option of two more years [31].

A bonus is used as an incentive and ensures gains for the contractor if he succeeds in reaching the objectives or fulfilling the demands. Penalties are often connected with other demands in the contract, and are enforced if the contractor fails to comply. Such expectations include the following [11]:

- Failure reports should be reported back to the system.

- Inspection remarks should be reported back to the system.

- Time to repair must be recorded, i.e. the time from when the contactor has been notified about a failure until the contractor is in place to start the repair.

- Mean time to repair failures should not exceed prescribed time limits.

- Inspections should adhere to prescribed time limits.

- Planned maintenance activities on the track should not be exceeded.

- Maintenance activities on the track should not cause train delays.

- All personnel working on the track must be informed about traffic and electrical safety demands.

Trafikverket has a wide network of combined databases which gather information from the railway network, and to which stakeholders have access depending on their needs to perform the outsourced activity (e.g. maintenance, performance studies, design improvements, etc.). The information related to signalling system found on these databases includes:

- System architecture (BIS database) [15,32]

- Generic documentation (BVDOC database)

- Project documentation (IDA database) [33]

- Corrective maintenance (0felia database) [34]

- Preventive maintenance inspections (BESSY database) [35]

- ATC design performance (PATCY database)

- Analysis of operation and maintenance performance (Duvan database)

Knowledge dissemination and distribution from Trafikverket to stakeholders is done by sharing access to the databases. Other methods are used as well, such as emails, documents, meetings and informal conversations. Knowledge transfer from stakeholders to Trafikverket takes the form of reports (in the case of delivered 
results) or person-to-person communication (email, phone, conversations, etc.). Knowledge transfer between personnel working on the same project comprises emails, shared databases, documents, meetings, informal conversations etc.

Two common concerns emerged in our interviews of stakeholder experts involved in the maintenance of railway signalling systems (maintenance contractors, Trafikverket and a consultancy). They all pointed out the risk of loss of knowledge and expertise as more tasks are outsourced, and they all thought Trafikverket should have a sufficient depth of knowledge to be able to manage the railway network efficiently.

Espling [11] studied the maintenance strategy for a railway infrastructure in a regulated environment by implementing benchmarking techniques to compare different case studies from the Swedish railway network. Four risk areas were identified when outsourcing maintenance activities: the risk of losing control over maintenance costs, asset condition (asset measuring data to analyse the asset degradation), safety demands (concerning the contractor's employees' knowledge of track safety and asset knowledge) and core competence and asset knowledge [11]. Data on maintenance costs and asset condition are required to perform life cycle cost (LCC) analyses; a lack of information will be problematic in studies of the effect of changes on the infrastructure during the maintenance phase of the life cycle.

Best practices on maintenance contracting include: goal-oriented maintenance contracts combined with incentives; scorecard perspectives, quality meetings and feedback on objectives; frequent meetings where top managers from the local areas participate; cooperation and open and clear dialogue; and the use of Root Cause analysis [11].

\section{Discussion and implications}

Data analysis shows that signalling systems play an important role in corrective maintenance. Given the number of work orders related to these systems, it seems clear that improving maintenance in this area would lead to an overall improvement of railway maintenance. A significant number of work orders recorded failure causes as "no failure found" or "not possible to identify the failure". Both require extra time spent on corrective maintenance; with better knowledge of the system, maintenance performance would improve.

Better knowledge of the system helps improve preventive maintenance and reduces the time to identify the failure. Better knowledge management would help identify best maintenance practices for signalling systems and would facilitate the transfer of this knowledge to all stakeholders who can benefit. This, in turn, would reduce the time spent on failure identification and reduce the number of NFFs in WOs. 
When outsourcing maintenance, there is a risk of losing the knowledge required to identify best practices related to maintenance activities. Since many stakeholders are involved in the maintenance of railway signalling systems, the knowledge is spread between them. To facilitate knowledge transfer between these stakeholders it is necessary to create new inter-organisational knowledge management processes. Some proposals have been developed, such a framework for benchmarking [11], or in the Toyota case, creating an identity through network-level knowledge-sharing routines [25]. Some of the measures implemented by Toyota could be applied to improve knowledge sharing among the stakeholders involved with railway signalling systems.

Integrating ideas from the relatively new Product-Service-System (PSS) theory area is another interesting possibility [36], as it could change how signalling systems and their maintenance are understood.

Suggested measures to improve inter-organisational knowledge management include the following:

- Creating an association of stakeholders would facilitate the creation of opportunities to share knowledge. It would foster the sense of belonging to the same community, and the belief that all members pursue the same objectives (optimise performance with minimum cost).

- Setting up a consulting division inside Trafikverket to support the stakeholders would incur an extra cost for Trafikverket, but it would help to keep knowledge inside Trafikverket and facilitate benchmarking best practices.

- Periodic intra- and inter-organisational meetings could improve tacit and explicit knowledge management. These meetings would provide a framework within which to exchange procedures and best practices and over time would become an inter-organisational structure for problem-solving and best practices identification.

- Other knowledge management strategies such as formal training in short courses, workshops or seminars for all stakeholders would provide additional ways to generate networking opportunities and knowledge transfer.

- Stakeholders could report their maintenance performance; this could be analysed by the railway's infrastructure manager to determine best practices.

- These best practices could be redistributed to all stakeholders and gathered in a common repository to safeguard knowledge and facilitate knowledge transfer among projects, stakeholders or locations.

- Finally, it would be interesting to consider expanding the knowledge network, not only to the maintenance companies but also to other stakeholders involved in signalling systems, including manufacturers and rolling stock owners. For instance, manufacturers could provide in-depth knowledge of the signalling systems and, in exchange, receive feedback on improving the design. As rolling stock owners have access to the signalling subsystems installed on board, they could give information on the performance of the whole signalling system. 
The goal is for the infrastructure manager and the stakeholders to understand that sharing knowledge will benefit everyone. Sharing consulting and problem-solving teams can increase both productivity and supplier performance, making knowledge sharing crucial for all stakeholders, from manufacturers to maintenance companies.

\section{Conclusions}

The purpose of this paper is to analyse the potential for improving interorganisational knowledge management in the maintenance of railway signalling systems and make concrete suggestions for improvements. It concludes the following:

- Signalling systems play an important role in corrective maintenance; thus, improving their maintenance would lead to an overall improvement of the railway maintenance. Furthermore, improving knowledge management processes would improve maintenance performance.

- Many stakeholders are involved in the maintenance and operation of railway signalling systems; sharing knowledge among these stakeholders is likely to benefit all of them.

- Proposals to improve inter-organisational knowledge management include the techniques used in the Toyota case and Espling's suggestions.

- Sharing knowledge would give stakeholders a holistic perspective of the maintenance and operation of the railway network and improve the effectiveness of the different organisations.

- To reduce the limitations of this study, future research should make use of indepth data analysis and other qualitative methodologies. Surveys could validate and quantify the results of interviews and quantify the feasibility of each improvement proposed here. Surveys should be given to all stakeholders.

\section{Acknowledgements}

The authors gratefully acknowledge the support of Trafikverket during this research. The Railway Research Centre (JVTC) and Trafikverket are acknowledged for their financial support.

\section{References}

[1] Trafikverket, "The Swedish transport administration annual report 2012", Rapport, Trafikverket, Borlänge, 2012.

[2] G. Alexandersson, S. Hulten, "The swedish railway deregulation path", Review of Network Economics, 7(1):18-36, 2008.

[3] M. Pěnička, "Formal approach to railway applications," in Lecture Notes in Computer Science (Including Subseries Lecture Notes in Artificial Intelligence and Lecture Notes in Bioinformatics), pp. 504-520-520, 2007. 
[4] S.C.B. De Souza, N. Anquetil, K.M. De Oliveira, "A study of the documentation essential to software maintenance", Proceedings of the 23rd International Conference on Design of Communication - Documenting and Designing for Pervasive Information, pp. 68-75, 2005.

[5] E.G. Berggren, "Efficient track maintenance: Methodology for combined analysis of condition data", Proceedings of the Institution of Mechanical Engineers, Part F: Journal of Rail and Rapid Transit, vol. 224, no. 5, pp. 353360, 2010.

[6] S. Kumar, U. Espling, U. Kumar, "Holistic procedure for rail maintenance in Sweden," Proceedings of the Institution of Mechanical Engineers, Part F: Journal of Rail and Rapid Transit, vol. 222, pp. 331-344, 2008.

[7] IEC 60300 (3-14): "Dependability Management - Part 3-14:Application Guide -Maintenance and Maintenance Support", International Electrotechnical Commission, Geneva, 2004.

[8] M. P. Iacono, M. Martinez, G. Mangia, C. Galdiero, "Knowledge creation and inter-organizational relationships: The development of innovation in the railway industry," Journal of Knowledge Management, vol. 16, pp. 604-616, 2012.

[9] M. A. Mansor, A. Ohsato, S. Sulaiman, "Knowledge management for maintenance activities in the manufacturing sector," International Journal of Automotive and Mechanical Engineering, vol. 5, pp. 612-621, 2012.

[10] J.D. Campbell, "Outsourcing in maintenance management - A valid alternative to self-provision", Journal of Quality in Maintenance Engineering, 1(3):18-24, 1995.

[11] U. Espling, "Maintenance strategy for a railway infrastructure in a regulated environment", doctoral thesis, Luleå University of Technology, Luleå, Sweden, 2007.

[12] M. Holmgren, "Maintenance-related losses at the Swedish Rail," Journal of Quality in Maintenance Engineering, vol. 11, pp. 5-18, 2005.

[13] A.P. Patra "Maintenance decision support models for railway infrastructure using RAMS \& LCC analyses", $\mathrm{PhD}$ thesis, Luleå University of Technology, Sweden, 2009.

[14] C. Stenström, A. Parida, D. Galar, "Link and effect model for performance improvement of railway infrastructure", Proceedings of the Institution of Mechanical Engineers, Part F: Journal of Rail and Rapid Transit, July 2013 vol. 227 no. 4 392-402, 2012.

[15] Trafikverket, "Railway infrastructure architecture on Trafikverket (Anläggningsstruktur järnväg inom Trafikverket)", Standard, BVS 811, Trafikverket, Borlänge, (in Swedish), 2012.

[16] J.T. Luxhøj, J.O. Riis, U. Thorsteinsson, "Trends and Perspectives in Industrial Maintenance Management," Journal of Manufacturing Systems, vol. 16, pp. 437-453, 1997.

[17] P. Ellstrom, "Integrating learning and work: Problems and prospects," Human Resource Development Quarterly, vol. 12, pp. 421-435, 2001.

[18] P. Söderholm, "A system view of the No Fault Found (NFF) phenomenon," Reliability Engineering \& System Safety, vol. 92, pp. 1-14, 1, 2007. 
[19] C. Hockley, P. Phillips, "The impact of no fault found on through-life engineering services," Journal of Quality in Maintenance Engineering, vol. 18, pp. 141-153, 2012.

[20] Y. Zhou, Q. Li, Y. Zuo, "Fault knowledge management in aircraft maintenance," Proceedings of 2009 8th International Conference on Reliability, Maintainability and Safety, ICRMS 2009, pp. 645-649, 2009.

[21] Y. Horiguchi, T. Sawaragi, Y. Kaneda, A. Nakajima, "Knowledge management framework to share technical know-how in organization," in Conference Proceedings - IEEE International Conference on Systems, Man and Cybernetics, pp. 1436-1441, 2004.

[22] M. Alavi, D.E. Leidner, "Review: Knowledge management and knowledge management systems: Conceptual foundations and research issues", MIS Quarterly: Management Information Systems, vol. 25, no. 1, pp. 107-136, 2001.

[23] S. Blumenberg, H.-T. Wagner, D. Beimborn, "Knowledge transfer processes in IT outsourcing relationships and their impact on shared knowledge and outsourcing performance", International Journal of Information Management, vol. 29, no. 5, pp. 342-352, 2009.

[24] I. Nonaka, "A dynamic theory of organizational knowledge", Organization Science, 5, pp. 14-37, 1994.

[25] J.H. Dyer, K. Nobeoka, "Creating and managing a high-performance knowledge-sharing network: The Toyota case," Strategic Manage. Journal, vol. 21, pp. 345-367, 2000 .

[26] P.J. Lane, M. Lubatkin, "Relative absorptive capacity and interorganizational learning," Strategic Management Journal, vol. 19, pp. 461-477, 1998.

[27] W. Tsai, "Knowledge transfer in intraorganizational networks: Effects of network position and absorptive capacity on business unit innovation and performance," Academy of Management Journal, vol. 44, pp. 996-1004, 2001.

[28] D. Lee, E. Van Den Steen, "Managing know-how," Management Science, vol. 56, pp. 270-285, 2010.

[29] M.G. Pecht, "Establishing a relationship between warranty and reliability," IEEE Transactions on Electronics Packaging Manufacturing, vol. 29, pp. 184190, 2006.

[30] R. Granström, P. Söderholm, "Condition monitoring of railway wheels and no fault found problems," International Journal of COMADEM, vol. 12, pp. 4653, 2009.

[31] C. Stenström, "Maintenance performance measurement of railway infrastructure with focus on the Swedish network", technical report, Luleå University of Technology, Sweden, 2012.

[32] Banverket, "BIS - Information requirements (BIS - Informationskrav, Ajourhållningsansvar)", Regulation BVF 810.0, Banverket, Borlänge, (in Swedish), 2008.

[33] Banverket, "Methodology Guidelines for the management of administrative data (Metodanvisningar för hantering av förvaltningsdata i IDA2000)", BVH 584.41, Handbook, Banverket, Borlänge, (in Swedish), 2004. 
[34] Trafikverket, "Manual - Use of Ofelia for analysis (Handledning - Att använda Ofelia för Analytiker)", Rapport, Trafikverket, Borlänge, (in Swedish), 2010.

[35] Trafikverket, "Inspection system for railway, Bessy (Besiktningssystemet för järnväg, Bessy)", Technical document, TDOK 2011:244, Trafikverket, Borlänge, (in Swedish), 2012.

[36] S. Lingegård, "Integrated Product Service Offerings for Rail Infrastructure Potential Benefits and Challenges", licentiate thesis, Linköping Studies in Science and Technology, Linköping, Sweden, 2012. 